\title{
Classification of waste as hazardous or non-hazardous: the cases of ash and slag
}

\author{
R. Sjöblom \\ Tekedo AB, Sweden \\ Luleå University of Technology, Sweden
}

\begin{abstract}
Anyone who owns and manages waste is obligated by law to know if it is hazardous or non-hazardous. However, proper classification of waste from incineration and combustion facilities as well as from steel mills may initially appear as a "mission impossible". In such waste, oxides of various elements appear in the form of various phases with non-stoichiometric and varying compositions that do not appear in the data bases on hazardous properties of various substances. The trace elements - which are the ones of highest significance for the classification - do not form phases of their own but are included in the phases formed by the major elements in the form of solid solution. Different batches of waste may have different ranges of compositions rendering direct testing an insurmountable task.

A method is presented by means of which such residues can be classified in a conservative but still reasonably realistic and feasible manner.

According to this method, elements of interest are regarded as if they appeared as simple oxides or as mixed oxides with iron. These reference substances are selected in such a manner that they can be found in databases on hazardous properties of various substances. Such data of the reference substances can then be used together with data from chemical analysis to calculate whether the waste in question is hazardous or non-hazardous.

This approach has been pursued in Sweden at more than 30 plants with good results.

It is anticipated that the method - after adjustment - can be used also under upcoming new legislation.

Keywords: waste, hazardous, classification, oxide, ash, slag, directive.
\end{abstract}




\section{Introduction}

\subsection{Classification of ash and slag}

Classification of waste into hazardous and non-hazardous governs how the waste may be managed. It is imperative that all waste that actually is hazardous also becomes classified as such. By this, adequate measures are to be taken in order to protect health and the environment.

It is also very important that waste that can be shown to be non-hazardous also becomes classified as such. This enables requirements to be met on sustainability, in terms of facilitating recycling and thereby conservation of resources. Resources can be conserved also in the case when no use can be found for the waste since, at least in Sweden, classification as non-hazardous justifies disposal at a landfill for non-hazardous waste.

Under the legislation in the European Union, classification is relatively straightforward for many categories of waste. For other categories, e.g. combustion residues and certain residues from the steel industry, classification is far from trivial. Actual forms of occurrence are usually very complicated, and the actual chemical species do not occur in the data bases for hazardous properties of various substances (see further below).

According to previous legislation, classification was made solely on the basis of what category a certain waste belonged to. Since the year 2002, classification in Sweden as well as in other European countries is based mainly on the actual hazardous properties of the waste in question.

These properties are to be determined in similar but not identical ways as compared to the rules for labelling of chemical products.

The two cases are not equivalent, however. The composition of chemical products is usually carefully selected and maintained at narrow intervals as a result of quality assurance and control. This makes the prerequisites for labelling part of the design criteria. The composition of waste is for the most part a result of other optimizations. In particular, the composition of waste can vary considerably, e.g. in ash as a result of variations in the fuel, type of furnace, operation parameters and point of exit.

The issue of classification is of great significance to the industries involved as well as to society. District heating facilities and furnaces in the forestry industry in Sweden generate around 1.5 million tonnes of ash annually. Most of this ash is being sent to landfills, where it is either landfilled as waste or recycled as a construction material. Today, ash constitutes by far the largest category of waste that is being landfilled.

Significant volumes of waste are generated also at steel mills. However, most of the slag is by-product and not waste.

The need for classification and associated management of waste in the form of ash and slag has prompted branch research organisations as well as individual companies to develop a method by means of which such classification can be carried out in a cautious but at the same time reasonably realistic manner. It is 
also required that the method be feasible, so that it can be put to use even for relatively modest quantities of a certain batch or stream of waste.

\subsection{Legal prerequisites}

\subsubsection{Glossary}

Directive European Union decision that member countries are obligated to implement in national legislation

Ordinance

Swedish legislation issued by the Government

Regulation:

(1) EU legislation that is directly applicable to legal entities

(2) Swedish legislation issued by a Competent Authority

Substance

A legal entity that may have little to do with what is referred to as substances and molecules in textbooks on chemistry

\subsubsection{Waste and not waste}

The relatively new so-called framework directive of waste [1] defines when an object or a material is waste and not waste. In particular, it is clarified when

- a production residue is a by-product and when it is waste, and

- when something that was waste has ceased to be waste.

At present, the EU Commission is struggling with defining boundaries for different categories, and further EU regulations are to be expected.

Different legal acts apply to waste and not waste.

\subsubsection{Products}

Products that are not articles (e.g., chemical products are not articles) are either regarded as substances or as mixtures of substances.

Substances and mixtures of substances have to be labelled. At present, substances have to be labelled according to CLP (Classification, Labelling, and Packaging) [2], whilst mixtures can be labelled according to either CLP or DPD (Dangerous Preparations Directive) [3]. Labelling under DPD is not allowed after mid-2015. DPD is part of the old legislation on labelling that also comprised DSD (Dangerous Substances Directive) [4] that refers to substances. DSD and DPD have been implemented into Swedish legislation primarily by a regulation by the Swedish Chemicals Agency [5].

The main purpose of the labelling of chemical products is to inform anyone that handles or uses a chemical about any potential hazards involved.

Most substances also have to be registered under REACH [6].

CLP refers to substances managed within the EU. There is a similar system for international transport called GHS (Globally Harmonized System) [7].

\subsubsection{Waste}

The legislation on waste does not require any labelling such as is the case for chemical products. Instead, waste is classified as either hazardous or nonhazardous. Very generally, labelling according to DSD/DPD with symbol of danger approximately generates classification as hazardous if the chemical product in question has become waste. 
At the time of preparation of this paper (April 2012), the rules for classification of waste $[1,8]$ still refer to the DSD/DPD system. New legislation based on CLP is in progress at the EU Commission, and will at the earliest be decided on in the summer of 2012.

At present, waste having any of the following properties is to be regarded as hazardous based on quantitative criteria: highly toxic*, toxic*, harmful*, corrosive*, irritant*, carcinogenic, teratogenic and mutagenic. Label with * implies that the sum should be taken over all constituents having the property in question, whilst it is only required to consider the highest concentrations in the other cases.

The system is based on tests on individual substances. Test results above certain levels give rise to labelling with certain so-called risk phrases which, in turn, generate labelling with symbols of danger according to certain rules for chemical products, and classification as hazardous according to certain similar rules in the case of waste.

For preparations (mixtures) certain algebraic expressions are to be used to assess the risk phrases and symbols of danger in the case of chemical products, and certain similar algebraic expressions, but simpler, are to be used to assess whether a waste is hazardous or not.

\section{Objective and scope}

The method mentioned in Section 1.1 for the classification of waste into the categories hazardous and non-hazardous has been in use in Sweden at various stages of development for more than 10 years. A few summaries (and one full report) have been published in English [9-13], but the bulk of the material has been published in Swedish [14-18] in order to facilitate the use of the method. The work on residues from the steel industry has not been published in any openly available series. The present paper summarizes the work carried out and the results obtained on classification of ashes and slags in Sweden.

The main objective of the present work is as follows:

- To determine strategy as to whether ash and slag should be regarded as one or more substances

- To identify and select reference substances for the analysis

The objective is also:

- To summarize experiences made

- To present an outlook for the future in view of new legislation that is underway

The method was first developed for ash, but has become validated and used also for waste from the steel industry.

The present conference paper represents a summary of several projects. Work is in progress to present this work in full in the form of two journal papers, one on the method for classification, and the other on solid solubility. They will include more comprehensive references, including references to procedures for classification used in other European countries. 


\section{Ash and slag as one or more substances}

The first consideration to make when waste comprising complex oxides is to be classified is to select whether the waste in question should be regarded as one or more substances. In other words, one has to decide whether e.g. ash should be tested as it is for the various properties mentioned in Section 1.2.4 above, or if it should be regarded as a mixture of substances, preferably with known hazardous properties for each of the substances.

The answer to this question depends on the kind of variations in the content of impurities that occur between the various batches and streams of the waste in question. If they are all about the same, then this indicates that it could be preferable to regard the waste as one substance. On the other hand, if they are all different, then this indicates that it is probably advantageous to regard the waste as a mixture. This situation is illustrated for a few batches and two impurities or contaminants in Figure 1.

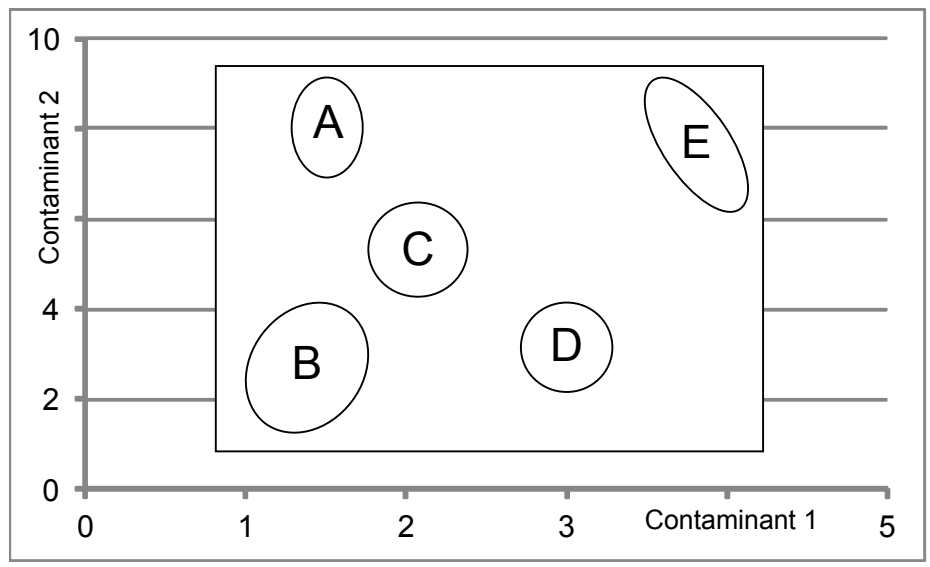

Figure 1: The rectangle illustrates the area that needs to be covered if ashes A-E were to be regarded as one substance or one blend.

Analyses have indicated that ashes and some slags appear in moderate volumes and varying contents of impurities. In these cases the route of mixture of substances has been pursued.

Other slags, including blast furnace slag, appear in large volumes with low and constant levels of impurities. In addition, these slags have proven very useful for a number of applications. They are therefore considered not to be waste. Blast furnace slag is thus a by-product and has been registered under REACH. Such registration is possible only for substances.

The next question is what legal basis may exist for regarding e.g. an ash as a mixture of substances. This was found to be appropriate already in the first project on classification that leads to an open report [14].

Later information searches [11] unveiled a relevant report from the OECD [19] as well as a guidance document from ECHA (the European Chemicals 
Agency) [20]. More recently, the United Nations has published a relevant guidance document [21] for GHS.

All of these documents support the hazard evaluation of ash and slag to be based on the concept of a mixture of substances. The identifications of reference substances described in the following are in concordance with these documents. This includes the role of testing of water availability as well as the analysis of mixed oxide phases. Reference [20] mentions, in particular, the role of iron and the scavenging function that spinel phases may serve.

The alternative of mixture of substances offers the great advantage that substances appearing in data bases on hazardous properties might be utilised for the assessment of the hazardous properties of the mixture.

A substance, e.g. a simple oxide that can represent an element in the waste in this way is referred to as a reference substance.

It might be added that the concept of ash and slag being mixtures is possible to utilize also under REACH in spite of the fact that REACH refers to substances [11]. In the case of Sweden, two ashes and most of the slags from the steel industry have been registered under REACH, but without utilizing any such possibilities.

\section{Forms of occurrence of trace elements}

\subsection{Introduction}

This section (Section 4) deals almost exclusively with the chemistry of ash. The chemistries of the various streams of waste generated at iron ore reduction and steel melting facilities have also been investigated. The main differences are that steel mill residues typically are formed at higher temperatures, have narrower ranges of major elements, and less of such trace elements that may influence the classification. Consequently, Section 5 is equally applicable to waste from the steel industry.

The description in the following refers to a fire grate furnace, but it is largely relevant also to a fluidized bed furnace.

The main fuels are bio-fuels and waste, whilst coal represents only a minor fraction in Sweden.

\subsection{High temperature}

Two main fractions of ash are generated, bottom ash and fly ash. Bottom ash is usually removed from the furnace by motion of the grate into a water lock and thus exits the furnace in a wet form.

Fly ash comprises material that has left the furnace by the fumes, and is thus somewhat enriched with regard to volatile elements and compounds. The cooling of the fumes that takes place as they pass the tubes containing water and steam leads to a fractional condensation onto the particles in the fumes. Most of the fly ash is removed from the fumes by electrostatic or mechanical filters. 
The temperature is not high enough to cause a complete melting of the ashes, as is more or less the case for combustion of coal powder. Nonetheless, a considerable fraction of the fly ash is in a glass form that can be very reactive.

There is usually a considerable fraction of iron in bottom ash and fly ash. Iron tends to go into phases in which it is a major or even dominating element, and the situation in this regard is similar to that in metamorphic rock.

Contrary to wide-spread misconception, and in concordance with findings in inorganic chemistry and geochemistry since decades, the minor elements do for the most part not form phases in which they are major elements $[12,18]$. This has also recently been observed experimentally [22]. Instead, the minor elements appear in solid solution in the phases formed by the major elements. This means that the trace elements are dispersed, atom by atom, in the crystal lattices of such phases.

In particular, the above mentioned spinel family of crystal structures has numerous members that are well known for their scavenging of most of the transition elements as well as a number of other elements. An example of a spinel is magnetite with the chemical formula $\mathrm{Fe}_{3} \mathrm{O}_{4}$.

Details in the chemistries with regard to alkali silicate formation together with availability of chlorine, sodium and potassium in the gas phase (as well as the oxygen fugacity) dictate whether or not elements like lead and zinc may condense in the form of chlorides.

\subsection{Low temperature}

It is assumed that the ash is contacted with water and air after it has exited the furnace. This is clearly the case for most bottom ashes which pass a water lock. To at least some extent, prompt wetting also takes place for most fly ashes which are subjected to water spray after exiting for control of dust. With few exceptions, ash is kept in the open air subjected to rainfall.

The high temperature phases formed during combustion and incineration are for the most part not stable at ambient temperature and in contact with water and air. Rapidly occurring reactions include hydrolysis leading to formation of hydroxides and hydrates. Zinc and lead chlorides are e.g. rapidly hydrolysed and converted to other phases that show a low availability of these elements to water.

Usually, the $\mathrm{pH}$ is larger than around 10, and often around 12,5 which indicates presence of portlandite $\left(\mathrm{Ca}(\mathrm{OH})_{2}\right)$. Such high $\mathrm{pH}$ conditions mean that silicon and aluminum oxides are somewhat water soluble and thereby also reactive.

Ash in contact with water and air matures or ages during days to many years. After a few years, the $\mathrm{pH}$ value may be less than 10 , even in the absence of carbonation.

The leaching properties of ash are the main criterion for acceptance to landfilling. Although the relevant standard explicitly states that it is applicable only to such substances that do not react with the leachant, the accredited laboratories nonetheless perform the test on fresh ash without even mentioning that they deviate from the standard. 
Four fly ashes were moisturized with different amounts of water and aged during different times after which they were subjected to the standard 24 hours batch leach test. [17] The example of the leaching of zinc in this experiment is shown in Figure 2. As can be seen from the figure, ageing at moist conditions for as little as one week can lead to a decrease in the availability to water by considerably more than an order of magnitude.

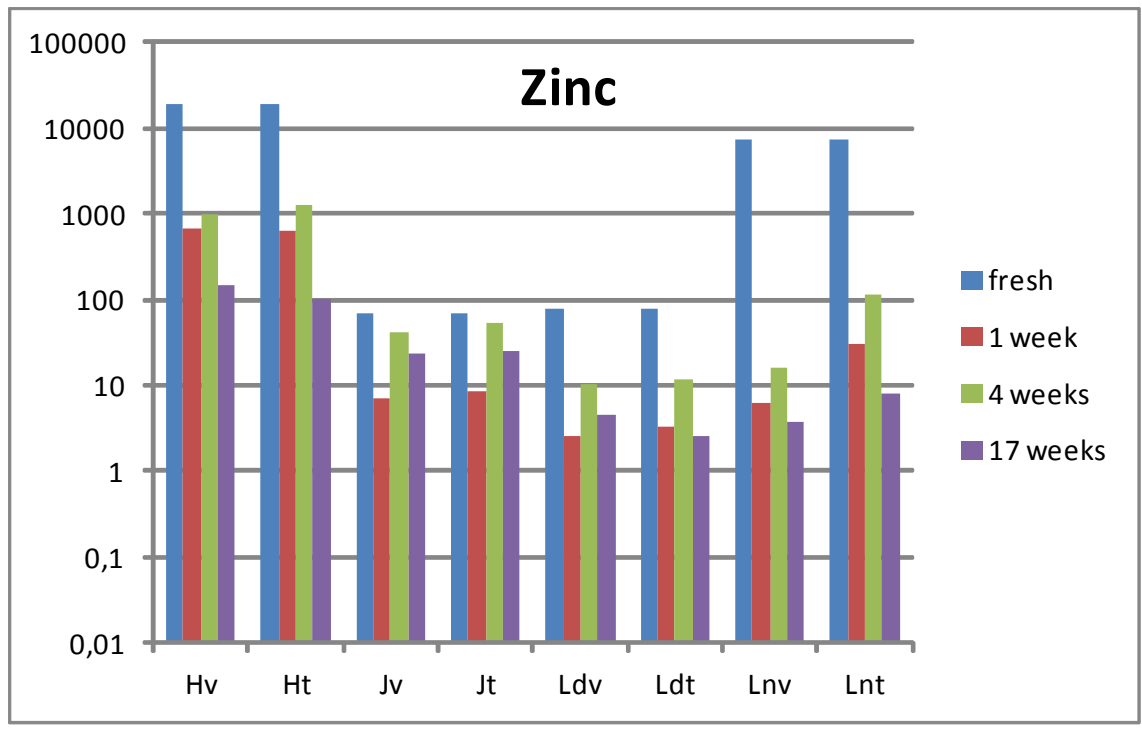

Figure 2: Leaching of zinc (in $\mathrm{mg} / \mathrm{kg}$ dry weight, $\mathrm{L} / \mathrm{S}=10$ litres $/ \mathrm{kg}$ ) from four different fly ashes $(\mathrm{H}, \mathrm{J}, \mathrm{Ld}$ and $\mathrm{Ln})$ after ageing during different times and at two different moisture contents $(v>t)$.

Leach tests can be very helpful in assuring that the selection of reference substances is not overly optimistic.

Information searches have indicated that the significance of solid solubility is probably no less at low temperature as compared to high.

\section{Selection of reference substances}

\subsection{Basis for selection}

The description of the chemical properties of ash and other mixed oxide wastes in Section 4 was used to in the work to identify reference substances. Such substances must reflect the actual properties of an element in oxide form in the waste in question in a conservative but not overly pessimistic way. The reference substance must appear in the databases that exist on hazardous properties of various substances. The data base used in the present work is the one that is included in [5]. Formulas for the calculations can be found in [8], see also [5]. The reference substances are identified and selected in Sections 5.2 and 5.3. 


\subsection{Simple oxides and chlorides}

Careful reviews of the chemistries of the simple oxides of relevant trace elements lead to the selection of the following substances: As-III, Ba-II, Co-II/III, Cu-II, Cr-VI, Mo-VI, Ni-II, Pb-II, Sb-III, V-V and Zn-II. Please note that the oxidation numbers selected do not always correspond to the most likely ones in the chemical environment in question. Instead, the most pessimistic alternatives were selected in cases of ambiguity. For instance, Sb-III was selected instead of the more likely $\mathrm{Sb}-\mathrm{V}$ in the high $\mathrm{pH}$ conditions in question.

Chloride forms were selected for $\mathrm{Hg}$-II and Cd-II for similar reasons.

\subsection{Mixed oxides with solid solution}

It was concluded in Section 4.1 that the actual form of the various trace elements is probably solid solution in phases formed by the major elements. This renders the trace elements inaccessible to any water phase, since the major elements for the most part form phases that are more or less insoluble in water.

Actually, solid solution in iron and manganese oxides is the main reason why the sea is so clean in spite of the fact that the crust has been exposed to recurrent rainfall under oxidizing conditions for more than a billion years.

Mixed oxides with iron renders $\mathrm{Cr}, \mathrm{Ni}$ and $\mathrm{Zn}$ particularly inaccessible to water, and such oxides therefore do not possess any hazardous properties.

It should specifically be noted that such solid solution strongly stabilizes $\mathrm{Cr}$ III and destabilizes Cr-VI, even under alkaline conditions.

Caution is required in order not to be overly optimistic. Therefore, leach tests are recommended to ensure that the water availability is actually low, as expected. Soluble fractions should always be regarded as simple oxide with a large safety margin since the assessment is uncertain. The caution should also include checking that the content of iron in the waste exceeds that of the elements in question by an appropriate factor.

\section{Conclusions and comments}

\subsection{Summary of the above conclusions}

Classification of waste from combustion and incineration facilities as well as steel works may initially appear as a "mission impossible" due to the complexity of the legislation as well as that of the chemistry.

However, it is shown that the legislation is open for the approach of regarding such waste as a mixture of simple oxides with known hazardous properties. These properties can then be used together with data on elementary analysis to calculate the hazardous properties of the "mixture".

It is the content of minor elements that renders some of these wastes hazardous. The minor elements rarely form phases of their own in which they are major elements. Instead, they are dispersed - one by one - in the phases formed by the major elements. Such mixed oxides usually show a much lower 
availability of minor elements to the water phase as compared to the corresponding simple oxides.

The elements chromium, nickel and zinc show a large tendency to form mixed oxides with iron, and this renders them inaccessible in ashes and slags.

Caution is warranted in order to avoid any overly optimistic evaluations. It is recommended that that leach tests be carried out on waste that has been aged under moist conditions to ensure that the assessment of reference substances is conservative. In the case of mixed oxides with iron it is essential that the content of iron by far exceeds that of the elements of interest.

\subsection{Classification experience}

The method described above has been used in practice for more than ten years and at more than 30 sites, mostly district heating plants, but also steel plants. Each site has typically had a few ashes or other oxide based wastes.

So far, the experience is good, and the classifications have been accepted by the enterprises as well as by the Authorities and Legal Courts.

\subsection{Outlook for the future}

It was mentioned above in Section 1.2 that new legislation for classification of waste is underway, and that the basis will be shifted from DSD/DPD to CLP. This is not merely an update. CLP is designed to be similar to GHS, and therefore, the limits for the test values that generate various labels are different. There are tables for conversion from DSD/DPD to CLP, but some "efficiency" is lost in the translation. The way of figuring is quite different in some cases, and especially for ecotoxic properties.

The EU Commission is currently working on a document that establishes how CLP will form the basis for the classification of waste into hazardous or nonhazardous. At present (April 2012) this document contains different alternatives, and details on the outcome cannot be known.

However, it is apparent that the presently presented method for assessment can function equally well under the new rules, although adaption will be required.

\section{Acknowledgements}

The work leading to the present paper has been supported - financially as well as otherwise - by the following: Avfall Sverige (Swedish Waste Management), Jernkontoret (the Swedish Steel Producers' Association), Naturvårdsverket (the Swedish Environmental Protection Agency), Svenska Energiaskor AB (Swedish Energy Ashes Company), Värmeforsk (the Swedish Thermal Engineering Research Association), Ångpanneföreningens Forskningsstiftelse (Ångpanneföreningen's Foundation for Research and Development), together with more than 30 sites with district heating facilities, paper mills and steel mills (the latter includes SSAB AB in Borlänge, Luleå and Oxelösund). All sources are hereby gratefully acknowledged. 


\section{References}

[1] Directive 2008/98/EC of the European Parliament and of the Council of 19 November 2008 on waste and repealing certain Directives.

[2] Regulation (EC) No 1272/2008 of the European Parliament and of the Council of 16 December 2008 on classification, labelling and packaging of substances and mixtures, amending and repealing Directives 67/548/EEC and 1999/45/EC, and amending Regulation (EC) No 1907/2006. This regulation is commonly referred to as CLP.

[3] Directive 1999/45/EC of the European Parliament and of the Council of 31 May 1999 concerning the approximation of the laws, regulations and administrative provisions of the Member States relating to the classification, packaging and labelling of dangerous preparations. It is commonly called the Dangerous Preparations Directive, or DPD.

[4] Council Directive 67/548/EEC of 27 June 1967 on the approximation of laws, regulations and administrative provisions relating to the classification, packaging and labelling of dangerous substances as amended taking account of changes up to 1/08/2008. It is commonly called the Dangerous Substances Directive, or DSD.

[5] Regulations of the Swedish Chemicals Agency on classification and labelling of chemical products. (Swedish title: Kemikalieinspektionens föreskrifter om klassificering och märkning av kemiska produkter). KIFS 2005:7.

[6] Regulation (EC) No 1907/2006 of the European Parliament and of the Council of 18 December 2006 concerning the Registration, Evaluation, Authorisation and Restriction of Chemicals (REACH), establishing a European Chemicals Agency, amending Directive 1999/45/EC and repealing Council Regulation (EEC) No 793/93 and Commission Regulation (EC) No 1488/94 as well as Council Directive 76/769/EEC and Commission Directives 91/155/EEC, 93/67/EEC, 93/105/EC and $2000 / 21 / E C$. This regulation is commonly referred to as REACH.

[7] Globally harmonized system of classification and labelling of chemicals (GHS), fourth revised edition. United Nations, 2011.

[8] Ordinance of waste (Swedish title: Avfallsförordning). SFS 2011:927.

[9] Sjöblom, R., Tham, G., Haglund, J.-E. and Sjöö, C., Environmental qualification of ash from wood-based recycled fuels for utilization in covers for landfills. Kalmar ECO-TECH '05 and The Second Baltic Symposium on Environmental Chemistry, November 28-29, 2005, Kalmar, Sweden.

[10] Sjöblom, R., Tham, G., Haglund, J.-E. and Ribbing, C., Classification of waste according to the European Union Directive 91/689/EEC on hazardous waste from a Swedish application perspective. CIWM Conference 12th - 16th June 2006, Paignton, Torbay, UK.

[11] Sjöblom, R. and Tivegård, A.-M., Methodology for qualification of woodbased ash according to REACH - prestudy. Värmeforsk (the Swedish Thermal Engineering Research Association), Report 1127, February, 2010. 
[12] Sjöblom, R. and Noläng, B., On the significance of solid solution in iron (hydr)oxides for immobilisation of potentially polluting elements in ashes. Proceedings of Ash Utilisation 2012, Ashes in a Sustainable Society, Värmeforsk, January 25-27, 2012, Stockholm, Sweden.

[13] Sjöblom, R. Hazard evaluation of ash under the new waste framework directive (2008/98/EC). Ibid.

[14] Adler, P., Haglund, J.-E.,. and Sjöblom, R. Guidance for classification of incineration residues according to the Ordinance of waste. (Swedish title: Vägledning för klassificering av förbränningsrester enligt Avfallsförordningen). Värmeforsk, Report 866, January, 2004.

[15] Sjöblom, R., Basis for selection of reference substance for zinc for classification of ash under the ordinance of waste. (Swedish title: Underlag för val av referenssubstans för zink inför klassning enligt Avfallsförordningen). Avfall Sverige (Swedish Waste Management), Report F2007:03, October, 2007.

[16] Sjöblom, R., Application of the ordinance of waste SFS 2001:1063, contribution to the knowledge base on residues from combustion and incineration. (Swedish title: Tillämpning av avfallsförordningen SFS 2001:1063; Bidrag till kunskapsbasen avseende förbränningsrester). Värmeforsk. Report 1103, March, 2009.

[17] Sjöblom, R., Pertinent methodology for basic characterization of ash for acceptance for landfilling. (Swedish title: Lämplig metodik för grundläggande karakterisering av aska för acceptans på deponi). Avfall Sverige, Report U2011:22, October, 2011.

[18] Sjöblom, R. and Noläng, B., The significance of solid solution in iron (hydr)oxides for stabilization of elements potentially harmful to health and environment. (Swedish title: Betydelsen av fast löslighet $i$ järn(hydr)oxider för fastläggning av potentiellt miljöstörande ämnen $i$ askor). Värmeforsk, Report 1198, November, 2011.

[19] Guidance Document on Transformation/Dissolution of Metals and Metal Compounds in Aqueous Media. OECD Environment, Health and Safety Publications Series on Testing and Assessment No. 29. OECD, Environment Directorate. Paris, April 2001.

[20] Guidance on information requirements and chemical safety assessment Chapter R.6: QSARs and grouping of chemicals. ECHA Guidance for the implementation of REACH. May 2008.

[21] Recommendations on the transport of dangerous goods, manual of tests and criteria, fifth revised edition. Annex 10, guidance on transformation/dissolution of metals and metal compounds in aqueous media. United Nations, 2009 (annex 10 was issued in 2011).

[22] Yunmei Wei, Takayuki Shimaoka, Amirhomayoun Saffarzadeh, Fumitake Takahashi. Alteration of municipal solid waste incineration bottom ash focusing on the evolution of iron-rich constituents. Waste Management, 31 pp 1992-2000, 2011. 